\title{
Multi-Criteria Decision Analysis for Hybrid Water Supply Systems
}

\author{
$\underline{\text { M. Sapkota }}^{\text {a }}$, M. Arora ${ }^{\text {a }}$ and H. Malano ${ }^{\text {a }}$ \\ ${ }^{a}$ Department of Infrastructure Engineering, Melbourne School of Engineering, University of \\ Melbourne, Victoria, 3010 \\ Email: mukta.sapkota@unimelb.edu.au
}

\begin{abstract}
Traditional urban water systems based on centralised only water supply are facing challenges to meet the increasing water demand due to increasing population in urban centres. These systems are also vulnerable to periodic drought and flooding due to climate change. For this reason, urban water managers around the world have been supporting the adoption of decentralised water supply options such as wastewater reuse, greywater reuse, rainwater harvesting and stormwater harvesting in combination with centralised system to aid with meeting water demand as well as flood mitigation and stream health restoration. In this paper, the combination of centralised water supply system (WSS) with the decentralised system is termed as hybrid water systems. These systems are relatively new and need to be evaluated using a comprehensive framework that can account for multiple aspects of hybrid water supply systems including interaction between centralised and decentralised system.
\end{abstract}

Integration of multiple objectives (such as supplying fit for purpose water, supply reliability of fit for purpose water, wastewater and stormwater discharge and contaminant loads in wastewater and stormwater) to evaluate the hybrid water supply systems can be effectively accomplished by multi-criteria decision aid techniques. Multi-criteria decision analysis (MCDA) requires users to assign the weights to considered criteria to reflect their relative importance. This paper describes weight elicitations in evaluating the various combinations of decentralised and centralised water supply systems.

Six performance measures (PMs) were identified in consultation with Victorian water utilities to evaluate the system performance. The identified PMs are: i) Reduction in potable water demand from centralised water supply system, ii) Reduction in wastewater discharges both flow rate and volume, iii) Reduction in contaminant concentration of wastewater flow, iv) Reduction in stormwater flows both intensity and volume, v) Reduction in contaminant loads from stormwater and vi) Improvement of supply reliability of fit for purpose water. Then, a questionnaire survey was conducted among three major stakeholder groups namely, water resource managers, water professionals, and consultants to derive the weights of the selected performance measures.

A simple usual preference function was deemed most suitable by the surveyors in order to assess various aspects of hybrid water supply scenarios. Also, it was found that preference measures became more complicated requiring knowledge from diverse disciplines. To overcome this challenge, the use of simple usual preference function was most suitable. Further, the survey results provided almost similar weights to each criterion, varying between 0.15 and 0.18 . This indicates the similar importance of all criteria. Also, none of the criteria was deemed as unimportant demonstrating the robustness of all the selected criteria. The elicited weights and preference function of the performance measures in this paper, provide necessary data required to model and evaluate the interactions between hybrid water supply systems.

Keywords: Hybrid water supply system, Multi-Criteria Decision Analysis (MCDA), weight elicitation, Performance measures (PMs) 


\section{INTRODUCTION}

Urban water systems provide a number of functions including the provision of clean water to support a variety of uses, removal of wastewater from users to prevent unhygienic conditions and removal of stormwater to avoid damage from flooding (Hellstrom et al. 2000). However, literature suggests that this approach may be failing to adequately address the ever increasing demand as the current systems are reaching their limits (Sapkota et al. 2013). The urban water systems are faced with a number of sustainability issues, such as the challenges of climate variability, increasing population and drought (Kodikara et al. 2010). To cope with such challenges, current urban water supply systems are not only dependent on traditional centralized sources but also include other alternative water supply options such as rainwater tanks, stormwater harvesting, greywater tanks and wastewater reuse (Sapkota et al. 2015). Such combination of centralized and decentralized water supply systems (hybrid water supply systems) do not have only one objective; instead, they need to consider a number of different points of view (Sapkota et al. 2016). MultiCriteria Decision-Analysis (MCDA) provides efficient tools to deal with such multi-objective problems (Abrishamchi et al. 2005).

There are several approaches that categorize the MCDA methods. According to Vincke (1992), three types are distinguished; multiple attribute utility theory, outranking techniques and interactive techniques. Outranking techniques attempt to find a ranking or partial ranking based on pair wise comparisons (Braune $e t$ al. 2009). The outranking methods are the most commonly used method as they are adaptable to real problems and more easily comprehended by decision makers (Al-Kloub et al. 1997). Most of the time, the situation exists when it is hard to decide if an alternative is better than the other alternative. The outranking methods take this into account by allowing a state of incomparability (van Moeffaert 2003). Moreover, the situation of weak preference is assumed, where one alternative is just slightly better than another one. Due to these advantages, PROMETHEE (Preference Ranking Organization METHod for Enrichment Evaluations) (Brans \& Mareschal 1994), one of the outranking methods, has been adopted for use in this study. PROMETHEE is a simple ranking method in conception and application compared with the other methods for multi-criteria analysis (Brans et al. 1986). This method is software driven, user friendly, provides direct interpretation of parameters and a sensitivity analysis (Al-Kloub et al. 1997), has successfully been applied in many fields and a number of researchers have used them in decision-making problems (Behzadian et al. 2010).

The PROMETHEE method requires two sets of information, criteria weights and their preference functions. This paper describes the procedure followed in obtaining the weights and preference functions of different criteria as listed in section 2. The elicitation of weights is very important as weights directly reflect the decision makers' preference on attributes of the decision problem. The Preference Function signifies the relative importance of one alternative over another with respect to the criteria under consideration. These weights and preference functions derived for each criterion are used as input to evaluate hybrid water supply systems which will be discussed in future publication.

\section{CASE STUDY - PREFERENCE MEASURES FOR HYBRID WATER SUPPLY SYSTEMS}

To evaluate hybrid water supply systems (WSS), various performance measures (criteria) were set in consultation with Victorian Water Utilities through a series of workshops and personal interviews (Sapkota et al. 2016). These included reduction in potable water demand from centralized WSS, reduction of wastewater generation, reduction of contaminant (Total Suspended Solids(TSS), Total Phosphorous (TP),Total Nitrogen (TN), BOD and COD) concentration in wastewater, reduction in stormwater flow, reduction in contaminant (TSS, TP, TN, BOD and COD) load in stormwater and supply reliability of fit for purpose water. These criteria values are obtained by water and contaminant balance analysis using Urban Volume and Quality Model (UVQ) (Mitchell \& Diaper 2006).

\section{PREFERENCE PARAMETERS IN PROMETHEE}

The basic principal of PROMETHEE is based on pair wise comparisons of alternatives along each recognized criterion (Behzadian et al. 2010). Alternatives are evaluated according to different criteria, which have to be maximized or minimized. In addition to this, PROMETHEE requires two types of information (Moglia et al. 2012), 1) Relative importance of Performance Measures (PMs) and objectives (represented by weights) and 2) Level of preference within each PM (represented by a 'Preference Function'). 


\subsection{Relative importance of Performance Measures (Weights)}

A decision maker (DM) often views one PM as more (or less) important than another because of various reasons including personal preferences which may be reasonably objective or completely subjective (Kodikara et al. 2010). To express these differences, it is important to derive a set of weights (or relative importance) of selected preference measures. Elicitation of meaningful weights is of utmost importance for any MCDA method as weights directly reflect the Decision Makers preferences on attributes of the decision making problem (Pomerol \& Barba-Romero 2000).

A questionnaire survey was conducted among water professionals, who make water services related decisions (personnel from water utilities, CSIRO, Universities, Australian Water Association and consultants) to determine the factors to be considered in the evaluation criteria and the relative importance (weight) of each criterion and sub criterion. This survey was conducted by email and respondents were asked to respond to each question by allocating a score between 1 and 5 using Likert type scale (5=Important; $4=$ Somewhat Important; $3=$ Neither Important nor Unimportant; $2=$ Somewhat Unimportant and $1=$ Unimportant). The survey was sent to 100 professionals of which 37 respondents completed the survey resulting in a response rate of 37 percent. The following equation was used to calculate the weight of each criterion from the rating given by $D M j$ :

$$
w_{c j}=r_{c j} / \sum_{c=1}^{m} r_{c j}
$$

Where, $w_{c j}$ and $r_{c j}$ are the weight and rating respectively, given by $D M_{j}$ to criterion $c . m$ is the number of criteria.

$$
w_{c}=\sum_{j=1}^{n} w_{c j}
$$

Where, wc is the weight for criterion $\mathrm{c}$ and $\mathrm{n}$ is the number of respondents.

When using Likert-type scales in a questionnaire survey, it is imperative to calculate the Cronbach's alpha coefficient for internal consistency reliability (Gliem and Gliem, 2003). Cronbach's Alpha provides a measure of the internal consistency of a test or scale. It ranges in value from 0 to 1 and the higher the score, the more reliable the generated scale is (Santos, 1999). George and Mallery (2003) suggest the following scale to judge this coefficient. A value $\geq 0.9$ (Excellent), $\geq 0.8$ (Good), $\geq 0.7$ (Acceptable), $\geq 0.6$ (Questionable) $\geq 0.5$ (Poor), and $<0.5$ (Unacceptable). The coefficient is calculated as:

$$
\alpha=\frac{n}{n-1}\left(1-\frac{\sum_{c=1}^{m} \sigma_{y_{c}}^{2}}{\sigma_{x}^{2}}\right)
$$

Where, $n$ is the number of criteria considered, $x$ is the total score given by each respondents, $\sigma_{x}^{2}$ is the variance of the observed total test scores, and $\sigma_{Y c}^{2}$ is the variance of component $c$ for the current sample of respondents.

\subsection{Preference Functions}

Preference Functions are intended to reveal the relative importance of one alternative over another with respect to the preference measure under consideration. There are six basic types of preference functions: i) Usual Criterion, ii) Quasi Criterion, iii) Criterion with Linear Preference, iv) Level Criterion, v) Criterion with Linear Preference and Indifference Area and vi) Gaussian criteria as shown in Figure 1(J. P. Brans \& Vincke, 1985). For each criterion, the value of indifference threshold, q; the value of a strict preference threshold, $p$; the value of an intermediate value between $p$ and $q$ has to be fixed. There is no formal method documented in the literature for determining the preference functions and associated thresholds (Kodikara et al., 2010). Most studies employ the direct method of asking decision makers to specify the appropriate preference functions and the thresholds (Inamdar, 2014; Kodikara et al., 2010; Mutikanga, Sharma, \& Vairavamoorthy, 2011). This study also uses the direct method of surveying preferences. A questionnaire survey was conducted among experts representing water professionals from Victorian water utilities to arrive at the preference functions. The respondents targeted for this survey are water resource managers, stormwater planners, water supply planners, wastewater planners and integrated urban water managers (1-2 from each 
group). A personalized invitation email was sent to each of them describing the purpose of the meeting (face to face and telephone meeting) and providing the associated project background information. During the meeting, a brief presentation was made to describe the study background and PROMETHEE concepts to determine the preference function. Participants were also provided with additional information in the form of separate documents describing the basic concepts of preference function as required by PROMETHEE. Following the introduction, they were asked to respond to the questionnaire provided.

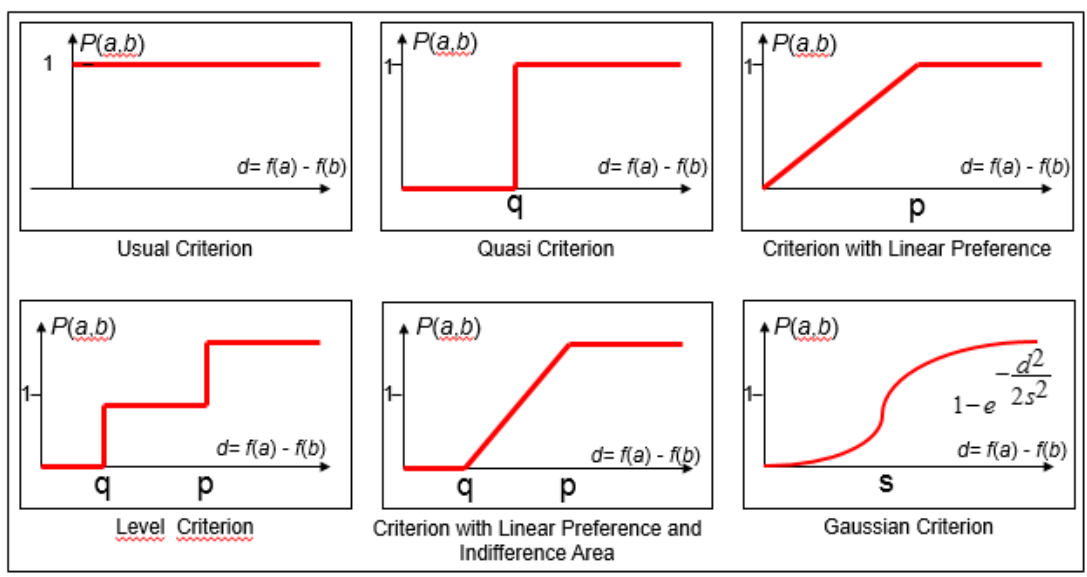

Figure 1. Preference criteria

\section{RESULTS AND DISCUSSIONS}

\subsection{Weights}

Figure 2 shows the relative importance of each of the six criteria elicited from the survey. The most important criterion is supply reliability of fit for purpose water. Over $70 \%$ of the respondents believe this criterion is important. Over 54\% of respondents consider four criteria as important: (i) Reduction in potable water demand from centralized WSS, (ii) Reduction of wastewater discharges, (iii) Reduction in contaminant loads from stormwater, and (iv) Supply reliability of fit for purpose water. Over $40 \%$ of respondents believe that all criteria are important. Moreover, all respondents believe that none of the criteria are unimportant. The responses show that all the criteria selected for the study are important which demonstrates that the set of criteria used in the study are robust. Also Cronbach's alpha is estimated to be 0.8 which means that the results from the survey are reliable (George \& Mallery 2003).

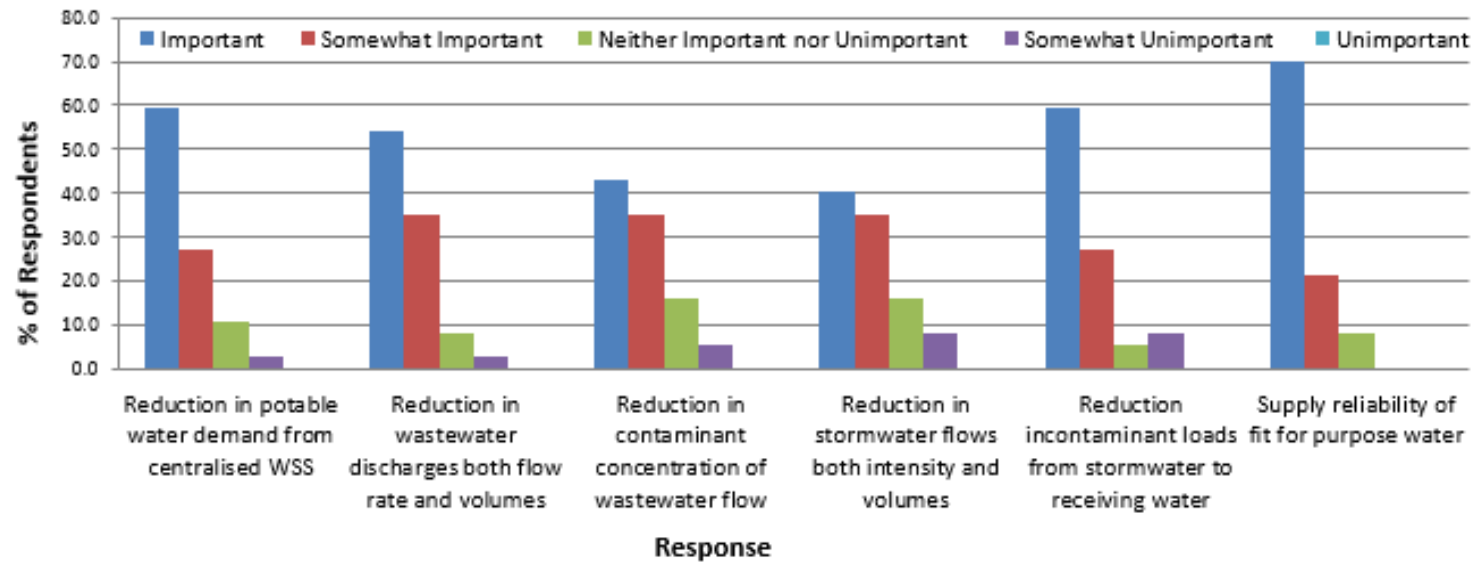

Figure 2. Survey results for the question: "Please rate each criteria based on the levels of importance from important to unimportant"

Figure 3 shows the calculated weight for each criterion. Supply reliability shows the highest weight $(0.18)$ followed by reduction in potable water demand, reduction in wastewater discharges and reduction in contaminants loads from stormwater with an average weight of 0.17 each. The weight of reduction in contaminants loads of wastewater flow is 0.16 while for reduction in stormwater discharges the weight is 0.15. The overall results show that the criteria have similar weights reflecting the equal importance of each criterion in evaluating hybrid water supply system options. 


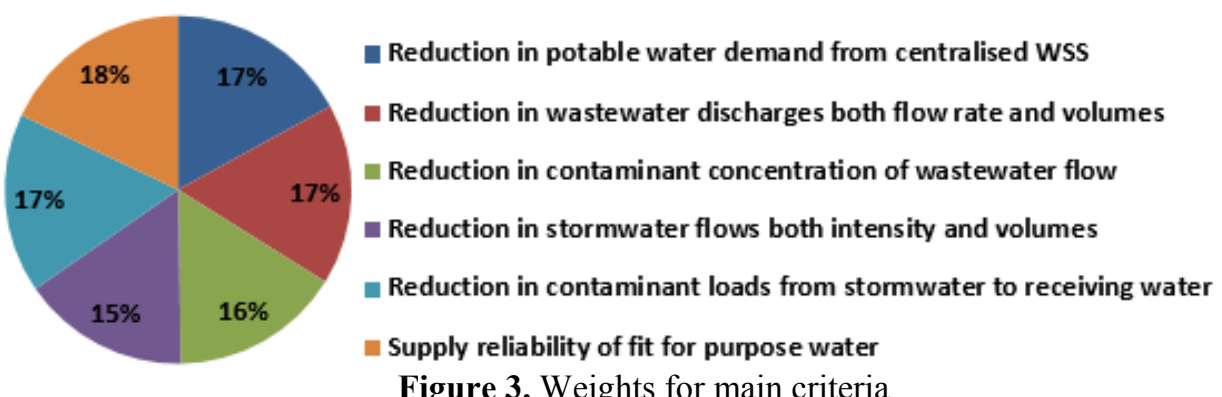

Table1 presents the calculated weight distribution between different sub-criteria for various criteria. For potable water supply and wastewater, the peak flow rate is found to make a greater contribution compared to the volume. On the other hand, stormwater flow volume contributes more relative to peak flow rate. For various contaminants in wastewater and stormwater, all contaminants have almost an equal weight thus indicating an equal importance of each sub-criterion.

Table 1. Weight for sub-criteria

\begin{tabular}{|c|c|c|}
\hline Criteria & Sub criteria & Weight \\
\hline \multirow{2}{*}{ Potable water supply } & Volume & 0.47 \\
\cline { 2 - 3 } & Peak & 0.53 \\
\hline \multirow{2}{*}{ Sewage flow } & Volume & 0.48 \\
\hline \multirow{2}{*}{ Stormwater flow } & Peak & 0.52 \\
\cline { 2 - 3 } & Volume & 0.52 \\
\cline { 2 - 3 } & Peak & 0.48 \\
\hline \multirow{3}{*}{ Sewage contaminants } & TN & 0.21 \\
\cline { 2 - 3 } & TP & 0.21 \\
\cline { 2 - 3 } & TSS & 0.20 \\
\cline { 2 - 3 } & BOD & 0.19 \\
\cline { 2 - 3 } & COD & 0.19 \\
\cline { 2 - 3 } & TN & 0.21 \\
\cline { 2 - 3 } & TP & 0.20 \\
\cline { 2 - 3 } & TSS & 0.19 \\
\cline { 2 - 3 } & BOD & 0.20 \\
\cline { 2 - 3 } & COD & 0.20 \\
\hline
\end{tabular}

Figure $4 \mathrm{a}$ depicts the relative importance of two sub-criteria for potable water supply. More than $60 \%$ of respondents believe that potable water supply volume is important. Over 37\% of respondents claim that both potable water supply volume and rate are important. Less than $3 \%$ of respondents considered potable water supply rate as unimportant. This result validates that both sub-criteria taken for potable water supply are important. Figure $4 \mathrm{~b}$ depicts the relative importance of two sub-criteria related to wastewater. Over $48 \%$ of respondents claim that both wastewater volume and rate are important. Less than $3 \%$ of respondents considered wastewater rate as unimportant. Based on these results, it can be said that both sub-criteria are important for wastewater. Figure $4 \mathrm{c}$ shows the relative importance of stormwater flow volume and rate. Almost $70 \%$ of respondents believe that stormwater flow rate is important. Over $45 \%$ of respondents claim that both stormwater flow rate and volume are important. None of the respondents believe that these subcriteria are unimportant. This confirms the importance of both sub-criteria in stormwater.

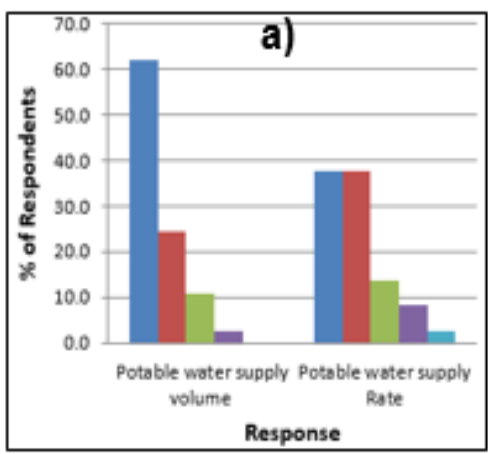

Important

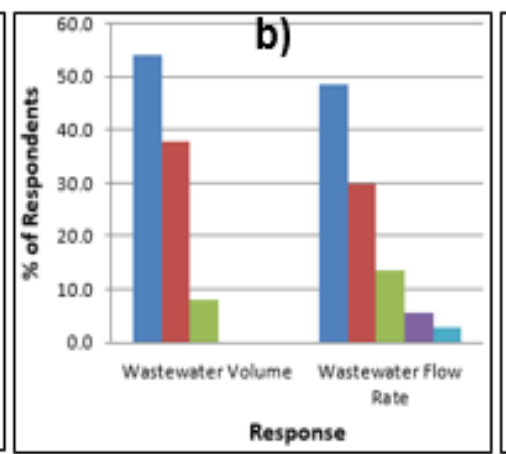

= Somewhat Important

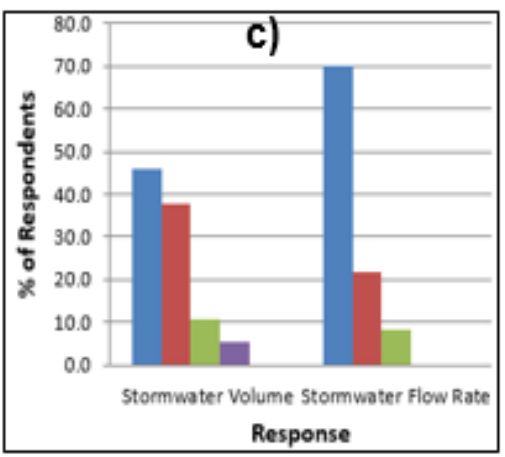

= Neither Important nor Unimportant

\section{= Somewhat Unimportant Unimportant}

Figure 4. Survey results for the question: Please rate the importance of volume and rate for a) potable water supply b) wastewater discharges and c) stormwater flow 
Figure 5a shows the relative importance of contaminants in wastewater discharge. Over $60 \%$ of respondents considered TN, BOD and COD as important while over $45 \%$ respondents believe that all contaminants considered in the study for wastewater discharges are important. Less than $6 \%$ think that all contaminants are unimportant. Hence, all the sub-criteria considered for wastewater concentration are important. Figure $5 \mathrm{~b}$ shows the relative importance of different contaminants on stormwater flow. Over 55\% of respondents consider TSS, TN and TP as important while over $40 \%$ of respondents believe that all contaminants considered in the study are important. Less than $3 \%$ think that all contaminants are unimportant. This result shows the importance of the sub-criteria considered for contaminants in stormwater flow.

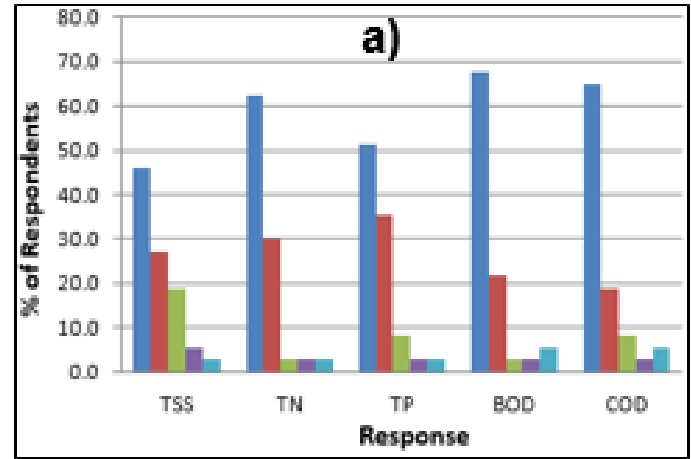

- Important

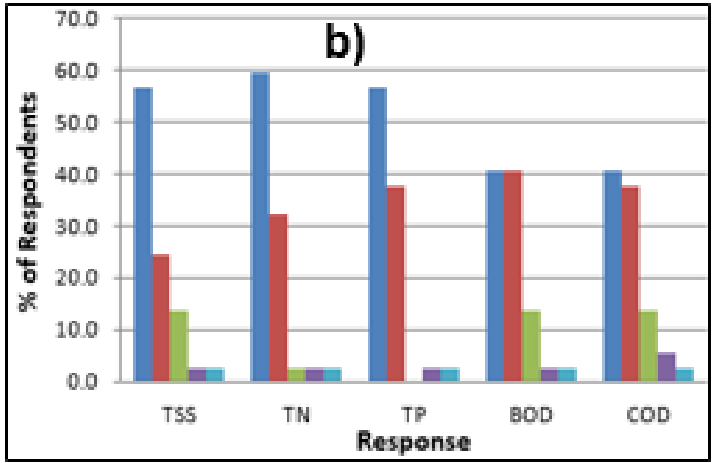

Neither Important nor Unimportant

Somewhat Unimportant

Unimportant

Figure 5. Survey results for the question: "Please rate the importance of different contaminants in a) wastewater discharges and b) stormwater flow"

Cronbach's alpha is also calculated to determine the relative importance and reliability of various subcriteria. Alpha values for potable water supply, wastewater flow, stormwater flow, wastewater contaminants and stormwater contaminants are $0.8,0.5,0.6,0.9$ and 0.9 , respectively. As alpha is $\geq 0.8$ for potable water supply, wastewater contaminants and stormwater contaminants, it can be considered that the overall results are very reliable. For wastewater and stormwater flow, reliability is poor but still acceptable as the alpha coefficient is 0.5 and 0.6 , respectively. To deal with this poor reliability, a weight sensitivity analysis should be conducted while conducting MCDA.

The respondents were also asked to list if any important criterion is missing. Almost $70 \%$ of respondents think the survey covers all criteria needed to evaluate the hybrid water supply system. One out of 37 respondents pointed out flood reduction as an additional criterion. However, flooding is considered indirectly by taking stormwater flow rate as one of the criteria. Also, 1 out of 37 respondents suggested using community participation as one of the criteria. Further, around $5 \%$ of respondents claim that the cost of hybrid WSS, social and behavioural aspect of people and impacts on ground water are important criteria. Around $8 \%$ of respondents raised the issue of energy use associated with such system and also impact on public health. These additional criteria have not been assessed in this study and further research can incorporate criteria such as cost, energy usage and impacts on groundwater.

\subsection{Preference functions}

The response to the questionnaire survey indicated that a usual preference function (Figure 1) would be the most appropriate. As preference measures required knowledge from many disciplines which makes the selection more complicated, the use of simple usual preference function is justified. In this study, various aspects of urban water such as stormwater, water supply and wastewater are assessed. Because the criteria used in the questionnaire are diverse, it became difficult for respondents to allocate the importance rating for the differences between criteria values. Rather, it seems that even if there is a very small difference in criterion value, the higher value option is selected. For example, one job offer is preferred over another if the salary offered is higher without assigning any importance to the difference. According to Podvezko and Podviezko (2010), the usual preference function can be used in such cases. Furthermore, according to Deshmukh (2013), the usual preference function is a good choice if the different levels of preference are considered quite different from each other, which is the case in this study. 


\section{CONCLUSION}

Recent literature suggests the need of combining for centralised and decentralised water supply options to create sustainable water systems to cope with future water challenges. Several criteria need to be considered to evaluate such hybrid water supply systems. These criteria have different preferences among different stakeholders. This paper describes a methodology used to elicit the preference measures. The elicitation process comprised questionnaire surveys to derive the weights and preference functions for preference measures. Overall, responses for the weight questionnaire survey show that all the criteria and sub-criteria selected for the study are important which ensures the robustness of criteria used for the study. Direct method used to elicit preference function shows usual preference function as an appropriate preference measure. The weights and preference function calculated here will be used in PROMETHEE method for Multi-criteria Decision Analysis to model and evaluate the performance of various hybrid water supply scenarios.

\section{REFERENCES}

Abrishamchi, A., A. Ebrahimian, M. Tajrishi \& M. A. Mariño (2005) Case Study: Application of Multicriteria Decision Making to Urban Water Supply. Journal of Water Resources Planning and Management, 131(4), 326-335.

Al-Kloub, B., T. Al-Shemmeri \& A. Pearman (1997) Theory and Methodology - The role of weights in multi-criteria decision aid, and the ranking of water projects in Jordan. European Journal of Operational Research, 99(2), 278-288.

Behzadian, M., R. B. Kazemzadeh, A. Albadvi \& M. Aghdasi (2010) PROMETHEE: A comprehensive literature review on methodologies and applications. European Journal of Operational Research, 200(1), $198-215$

Brans, J.-P. \& B. Mareschal (1994) The PROMCALC \& GAIA decision support system for multicriteria decision aid. Decision Support Systems, 12(4-5), 297-310.

Brans, J. P., P. Vincke \& B. Mareschal (1986) How to select and how to rank projects: The PROMETHEE method. European Journal of Operational Research, 24(2), 228-238.

Braune, I., A. Pinkwart \& M. Reeg (2009) Application of Multi-Criteria Analysis for the Evaluation of Sustainable Energy Systems-A Review of Recent Literature. 5th Dubrovnic Conference on Sustainable Development of Energy, Water and Environment Systems.

Deshmukh, S. C. (2013) Preference Ranking Organization Method Of Enrichment Evaluation (Promethee). International Summit on Waste Water Technology for Green Economy.

George, D. \& P. Mallery (2003) SPSS for Windows step by step: A simple guide and reference. Boston: Allyn \& Bacon.

Hellstrom, D., U. Jeppsson \& E. Karrman (2000) A framework for systems analysis of sustainable urban water management. Environmental Impact Assessment Review, 20, 311-321.

Kodikara, P. N., B. J. C. Perera \& M. D. U. P. Kularathna (2010) Stakeholder preference elicitation and modelling in multi-criteria decision analysis - A case study on urban water supply. European Journal of Operational Research, 206(1), 209-220.

Mitchell, V. G. \& C. Diaper (2006) Simulating the urban water and contaminant cycle. Environmental Modelling \& Software, 21, 129-134.

Moglia, M., D. Kinsman \& S. Maheepala (2012) Multi-criteria Decision Assessment Methods to Identify Total Water Cycle Management Strategies. Urban Water Security Research Alliance Technical Report.

Podvezko, V. \& A. Podviezko (2010) Dependence of Multi-Criteria Evaluation Result on Choice of Preference Functions and their Parameters. Technological \& Economic Development of Economy, 16(1), 143-158.

Pomerol, J.-C. \& S. Barba-Romero (2000) Multicriterion decision in management: principles and practice. Springer Science \& Business Media.

Sapkota, M., M. Arora, H. Malano, B. George, B. Nawarathna, A. Sharma \& M. Moglia (2013) Development of a framework to evaluate the hybrid water supply systems. 20th International Congress on Modelling and Simulation, pp. 2387-2393. Adelaide.

Sapkota, M., M. Arora, H. Malano, M. Moglia, A. Sharma, B. George \& F. Pamminger (2015) An Overview of Hybrid Water Supply Systems in the Context of Urban Water Management: Challenges and Opportunities. Water, 7(1), 153-174.

Sapkota, M., M. Arora, H. Malano, M. Moglia, A. Sharma, B. George \& F. Pamminger (2016) An Integrated Framework for Assessment of Hybrid Water Supply Systems. Water, 8(4).

van Moeffaert, D. (2003) Multi Criteria Decision Aid in Sustainable Urban Water Management. Swedish Urban Water Program.

Vincke, P. (1992) Multicriteria Decision-Aid. Wiley, West Sussex, England. 